\title{
ESTIMATION OF HOURLY GLOBAL SOLAR RADIATION IN EGYPT USING MATHEMATICAL MODEL
}

\section{Taha Ahmed Tawfik Hussein*}

\begin{abstract}
ABESTRACT
The main purpose of this paper is to develop a computer mathematical model which produces estimates of hourly average total solar radiation flux incident on the earth's surface under climate conditions of Delta, Egypt. Predictors for solar radiation have been developed because there is often a lack of representative solar radiation data in most countries. Cloudiness, atmospheric transmissivity, latitude and orientation of the Earth relative to the Sun, time of day, slope and aspect of the surface determine the spatial and temporal distribution of irradiance incident on a surface. Measured data were collected from the Solar-Meteorological stations of Agricultural Engineering Department at El-menoufiya University, El-Mansoura university and Belbees, in order to evaluate the present model. A comparison study between measured and predicted data has been carried out based on the main bias error and correlation coefficient. It can be concluded that the present model can be used to estimate the hourly average total solar radiation for El-menoufiya, ElMansoura, and Belbees with an excellent agreement
\end{abstract}

Keywords: Global radiation models; Solar radiation; Mathematical Model.

\section{INTRODUCTION}

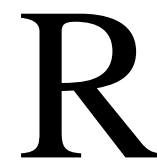
enewable energy is accepted as a key source for the future, not only for Egypt but also for the whole world. This is primarily due to fact that renewable energy resources have some advantages when compared to fossil fuels. However, environmental concerns and limited energy sources make renewable energy technology as a good candidate for fossil fuels. While Egypt has adequate solar energy potential to support its energy demand. Therefore, it is important to harness that resource in view to find solution to energy shortage and environmental degradation the country is

\footnotetext{
*Agricultural Engineering Department, Faculty of Agriculture, Minoufiya University, Shebin El-Kom, Egypt
} 
being faced to. Solar energy is which considered to be the most effective and economic alternative resource (El-Metwally, 2005).

In developing countries, such as Egypt, interest in solar energy applications has rapidly been growing for providing electricity and water supply in different areas. Solar radiation data is essential for modeling solar energy systems. Solar radiation is used directly to produce electricity using photovoltaic (PV) systems and solar thermal systems. Therefore, determination of global solar radiation at a location of study is required for the design and estimation of the thermal performance of any solar energy system. Solar radiation flux incident on the earth's surface is essential to architects and engineers for energy-efficient building designs and solar energy applications (Duffie and Beckman 2006; Sen, 2008).

The solar radiation has temporal and spatial variations. To collect this information, a network of solar monitoring stations equipped with pyranometers and data acquisition systems are generally established in the desired locations. However, the number of such stations in the network is usually not sufficient to provide solar radiation data of the desired areas, especially in developing countries. Therefore, it is necessary to develop methods to estimate the solar radiation on the basis of the more readily available meteorological data.

An alternative solution to this problem is to estimate solar radiation by using a modeling approach (Ibrahim et al.,1985; Dorvlo et al., 2002)

Modeling of solar radiation also provides an understanding of dynamics of solar radiation and it is clearly of great value in the design of solar energy conversion systems. Most locations in Egypt receive abundant solar radiation and hence solar energy technology can be beneficially applied in these regions. The solar radiation data are obtained from, quite few stations which have been measuring the daily solar radiation on a consistent basis. In the absence and shortage of reliable solar radiation data, hence, it is necessary to approximate solar radiation by the use of mathematical model in order to estimate and predict global solar radiation. These model uses meteorological data of the location under study. Knowledge of hourly solar radiation (direct and diffuse) on horizontal surface is essential to design solar energy devices. Hourly 
values of solar radiation enable us to derive very precise information about the performance of solar energy systems (Gopinathan, 1992).

Solar exposure estimates are important for a wide range of applications, mainly in the agricultural and to a lesser extent engineering sectors, and in research. Examples of use include: monitoring plant growth and disease control; evaporation and irrigation; architecture and building design e.g. power station condenser cooling systems; power generation; calculation of water requirements for crops; solar heating system design and use; skin cancer research; research into coral growth; weather and climate prediction models; solar powered car races. It is very common to design solar energy systems based on the hourly average of global solar radiation and other climatic data. Also, it is rather important to determine the beam and diffuse components of total radiation incident on a horizontal surface. Once, these components are determined, they can be transposed over tilted surfaces , and hence ,the short as well as the long-term performances of tilted flat plate collectors, photovoltaic modules and other solar devices can be estimated. Many models have been developed to estimate the amount of global solar radiation on horizontal surfaces using various climatic parameters ,such as sunshine duration, cloud cover, humidity, maximum and mini- mum ambient temperatures, wind speed, etc (Gopinathan, 1988; Halouani et al., 1993; Chegaar and Chibani, 2001; El-Sebaii and Trabea, 2005; Jacovides et al., 2006).

Estimation of solar radiation flux incident on different locations of Egypt either on horizontal surface or tilted surface have been studied by several researchers (Tadros, 2000 ;El-Sebaii and Trabea, 2005).

Mansoura, Shebin El-Kom and Belbees are Egyptian cities which located at latitude angles $31.045,30.54$ and $30.22^{\circ} \mathrm{N}$, respectively and they are one of the most solar energy abundant cities all days of the year as shown in fig(1). Therefore, solar energy devices can be operated with high performance. 


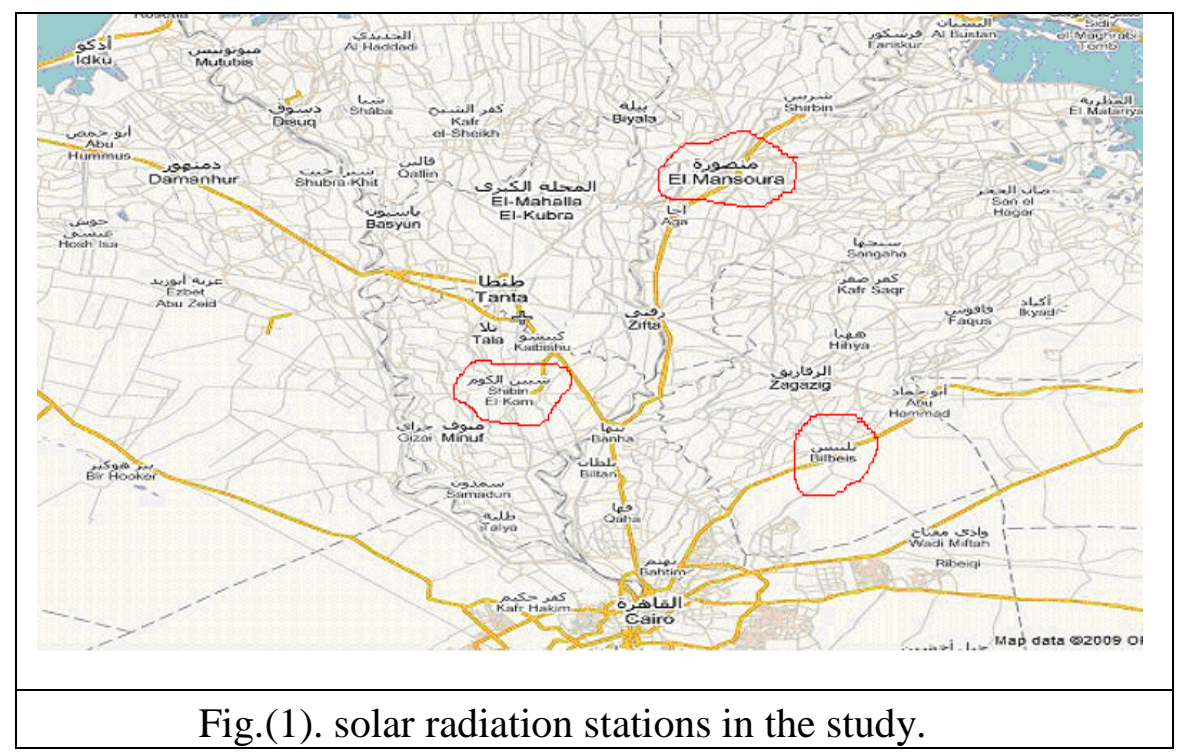

The main purpose of this paper is to develop a mathematical model to estimate the hourly global solar radiation on a horizontal surfaces in the cities using the available meteorological data, such as sunshine duration and cloud cover as well as maximum, minimum and daily mean of ambient temperature covering the year of 2009 .

\section{Model for computing radiation on the horizontal surface}

The total radiation received on the horizontal is a summation of the direct and diffuse radiation. (Parker, 1991; Duffie and Beckman, 2006).

$$
I_{H}=I_{b}+I_{d} \quad\left[\mathrm{Wm}^{-2}\right]
$$

where:

$\mathrm{I}_{\mathrm{H}}$ :The total solar radiation

$\mathrm{I}_{\mathrm{b}}$ : Clear-sky horizontal beam radiation.

$\mathrm{I}_{\mathrm{d}}$ : Clear-sky horizontal diffuse radiation

$\left[\mathrm{Wm}^{-2}\right]$

$\left[\mathrm{Wm}^{-2}\right]$

$\left[\mathrm{Wm}^{-2}\right]$

Hottel, (1976) has presented a technique for estimating the beam radiation transmitted through clear atmosphere as:

$$
I_{b}=I_{o n} \tau_{b} \operatorname{Cos} \theta_{z} \quad\left[\mathrm{Wm}^{-2}\right]
$$

Where :

$\mathrm{I}_{\mathrm{on}}$ : the extraterrestrial radiation measured on the plane normal to the radiation on the $\mathrm{n}$ day of the year.

$$
I_{o n}=I_{s c}\left[1+0.034 \operatorname{Cos}\left(\frac{360 n}{365.24}\right)\right] \quad\left[\mathrm{Wm}^{-2}\right]
$$


$\tau_{\text {b: }}$ The beam radiation transmitted

$\mathrm{I}_{\mathrm{sc}}$ : the solar constant $=1353 \mathrm{~W} / \mathrm{m}^{2}$

$\mathrm{n}$ : the number of the day from the first of January.

The number of the day (n) can be calculated as follows (Heindl and Koch, 1976):

$$
n=30(M)+0.6(M-3)-30.5+(N)
$$

$\mathrm{M}$ : month number from 1 to 12

$\mathrm{N}$ : day number of the month

The atmospheric transmittance for beam radiation, $\tau_{b}$, is given in the form:

$$
\tau_{b}=A_{0}+A_{1} \cdot \exp \left(\frac{-k}{\operatorname{Cos} \theta_{z}}\right)
$$

The constants $\mathrm{A}_{\mathrm{o}}, \mathrm{A} 1$, and $\mathrm{k}$ are for the standard atmosphere with 23 $\mathrm{km}$ visibility and are found from:

$$
\begin{aligned}
& \mathrm{A}_{0}=\mathrm{r}_{0} \mathrm{~A} *{ }_{0} \\
& \mathrm{~A}_{1}=\mathrm{r}_{1} \mathrm{~A} *{ }_{1} \\
& \mathrm{~K}=\mathrm{r}_{\mathrm{k}} \mathrm{k} *
\end{aligned}
$$

The factors $r_{0}, r_{1}$ and rk are climate correlations which are presented in table (1):

Table (1): Beam radiation correction factors for climate types From (hotel 1976;

Decarli et al., 1986; Parker, 1991).

\begin{tabular}{|l|c|c|c|}
\hline Climate types & $\mathrm{r}_{0}$ & $\mathrm{r}_{1}$ & $\mathrm{r}_{\mathrm{k}}$ \\
\hline Tropical & 0.95 & 0.98 & 1.02 \\
\hline \hline Mid-latitude summer & 0.97 & 0.99 & 1.02 \\
\hline Mid-latitude winter & 1.03 & 1.01 & 1.00 \\
\hline \hline Subarctic summer & 0.99 & 0.99 & 1.01 \\
\hline
\end{tabular}

These values are obtained as follows:

$$
\begin{aligned}
& A^{*}{ }_{0}=0.4237-0.00831(6-A)^{2} \\
& A^{*}{ }_{1}=0.5055-0.00595(6.5-A)^{2} \\
& k^{*}=0.2711-0.01858(2.5-A)^{2}
\end{aligned}
$$


$\theta_{\mathrm{z}}$ : the angle of incidence, $\theta_{\mathrm{z}}$, defines as the angle between the incoming beam solar rays and the normal to the horizontal surface. It can be calculated from the following equation.

$$
\theta_{z}=\operatorname{Cos}^{-1}[\operatorname{Cos} \phi \operatorname{Cos} \delta \operatorname{Cos} \omega+\operatorname{Sin} \phi \operatorname{Sin} \delta] \quad\left[{ }^{\circ}\right]
$$

$\phi$ : Latitude angle Which is the angular location north or south of the equator, northern hemisphere of the earth is positive and southern is negative $\left(-90^{\circ}<\varnothing>90^{\circ}\right)$.

$\delta$, is the angular position of the sun at solar noon with respect to the plane of the equator, north positive and south is negative $\left(-23.45^{\circ}<\delta>\right.$ $\left.23.45^{\circ}\right)$. It can be found from the following equation:-

$$
\left.\delta=23.45 \operatorname{Sin}\left[360 \frac{(284+n)}{365.25}\right] \quad \quad{ }^{\circ}\right]
$$

$\omega$ : Solar hour angle Which is the angular displacement of the sun east or west of the local meridian due to rotation of the earth on its axis at $15^{\circ}$ per hour, morning negative and afternoon is positive.

$$
\omega=(L A T-12) .15 \quad\left[{ }^{\circ}\right]
$$

Where, LAT. is the local apparent time (standard time).

Solar altitude angle $(\psi)$ Which is the angle between the sun's rays and the horizontal plane or its the angle between the horizontal and the line to the sun, that is, the complement of the zenith angle. This angle can be estimated from the following equation:-

$$
\psi=\operatorname{Sin}^{-1}[\operatorname{Cos} \phi \operatorname{Cos} \delta \operatorname{Cos} \omega+\operatorname{Sin} \phi \operatorname{Sin} \delta] \quad\left[^{\circ}\right]
$$

The equation for clear sky diffuse radiation is in the from:

$$
\begin{aligned}
& I_{d}=I_{o n} \cdot \tau_{d} \operatorname{Cos} \theta_{z} \\
& \tau_{d}=0.2710-0.2939 \times \tau_{b}
\end{aligned}
$$

Where $: \boldsymbol{\tau}_{\mathrm{d}}$, The diffuse radiation transmitted

These equation can be used to estimate the total standard clear sky radiation on a horizontal surface with incident angle, $\theta \mathrm{z}$ :

\section{Model for computing radiation on an inclined surface}

An improvement on this model, the isotropic diffuse model, was derived by Liu and Jordan, 1963; Parker, 1991; Duffie and Beckman, 2006). The radiation on the tilted surface was considered to include three components: beam, isotropic diffuse and solar radiation diffusely reflected from the surroundings (ground): 


$$
I_{T}=I_{T b}+I_{T d}+I_{T r} \quad\left[\mathrm{Wm}^{-2}\right]
$$

The terms in Equation (12) become :

$$
\begin{aligned}
& I_{T}=I_{b} R_{b}+I_{d} R_{d}+I_{H} \rho_{g} R_{r} \\
& =I_{b} \frac{\operatorname{Cos} \theta}{\operatorname{Cos} \theta_{z}}+I_{d} \frac{(1+\operatorname{Cos} \beta)}{2}+I_{H} \rho_{g} \frac{(1-\operatorname{Cos} \beta)}{2} \quad\left[\mathrm{Wm}^{-2}\right]
\end{aligned}
$$

Where:

$I_{T}$ : solar radiation absorbed at a tilted surface

$I_{T \mathrm{~b}}$ : beam solar radiation absorbed at a tilted surface

$I_{T d}$ :diffuse solar radiation absorbed at a tilted surface

$I_{T r}:$ reflected radiation from the surroundings

$\left[\mathrm{Wm}^{-2}\right]$

$\left[\mathrm{Wm}^{-2}\right]$

$\left[\mathrm{Wm}^{-2}\right]$

$R_{b}, R_{d}, R_{r}$ : The geometric factors, and

$\left[\mathrm{Wm}^{-2}\right]$

$R_{b}$, Ratio of beam radiation on the tilted surface to that on a horizontal surface at any time, leading in northern hemisphere, for $\gamma=0^{\circ}$, can be calculated exactly by appropriate use of Equation:

$$
R_{b}=\frac{\operatorname{Cos} \theta}{\operatorname{Cos} \theta_{z}}=\frac{\operatorname{Cos}(\phi-\beta) \operatorname{Cos} \delta \operatorname{Cos} \omega+\operatorname{Sin}(\phi-\beta) \operatorname{Sin} \delta}{\operatorname{Cos} \phi \operatorname{Cos} \delta \operatorname{Cos} \omega+\operatorname{Sin} \phi \operatorname{Sin} \delta} \quad\left[\mathrm{Wm}^{-2}\right]
$$

$\rho_{g}$ :The albedo of the ground.

$\beta$ : Tilt angle of the surface $=\phi\left(\right.$ Elminir et al.,2006) $\quad\left[{ }^{\circ}\right]$

$\theta$ : Incidence angle

$\gamma$ : surface-solar azimuth angle.

\section{Software tools}

The hourly solar radiation model was designed by using Simulink, which is an interactive tool for modeling, simulating and analyzing dynamic systems. Simulink provides a complete set of modeling tools that can be used to quickly develop detailed block diagrams of the systems. It integrates seamlessly with MATLAB, providing the user with immediate access to an extensive range of analysis. Simulink enables the building of graphical block diagrams, simulate dynamic systems, evaluate system performance and refine the designs (Palm, 1999).

\section{Model parameters:}

They are model inputs and can be divided into two groups. The first group includes parameters supplied by the user such as: the simulation time, latitude angle, surface azimuth, tilt angle for the inclined surface, 
day and month number which were used to calculate the solar radiation at the surface.The second group includes parameters taken from the literature such as: sea level, solar constant and the constants which are used to calculate the atmospheric transmittance for beam and diffuse radiation.

\section{RESULTS AND DISCUSSION}

The simulation results obtained from this model are considered "blind", since they have not been yet compared with the measured results from the selected regions. The comparison between measured and simulated results is very important in order to check out how far the simulated results are from the measured ones. It gives an idea, if there are any obvious errors and prospects about the possibility of improvements that can be achieved by such model.

To investigate the model's ability to predict and describe the hourly solar radiation during different times, simulations were compared with measurements for the selected regions (Shebin El-Kom, Belbees and ElMansoura). Fig.(2). presents the simulation results obtained assuming that the solar radiation reached the maximal value of $958 \mathrm{Wm}^{-2}$ in June. Comparing the results, we can see that all the used equations gave very good results.

The model gave the best estimate and have the smallest errors for the hourly values. The figure shows also that the simulated hourly solar radiation followed the same trends as that measured one but with some variations in timing of the peak values. The simulated data sometimes higher, sometimes lower or almost equal the measured variable.

The measured hourly solar radiation was plotted versus the predicted from simulation model as shown in Fig.(3). High correlation coefficient between the predicted and measured values was observed. The model gave accurate prediction of the hourly solar radiation. Nevertheless, the points scattered above and below the regression line show a good agreement between the simulated versus measured hourly solar radiation and over a reasonably prolonged duration. The coefficient of determination during the simulation period were $0.9851,0.9945$ and 0.9883 for Shebin El-kom, Belbees and ElMansoura respectively. 


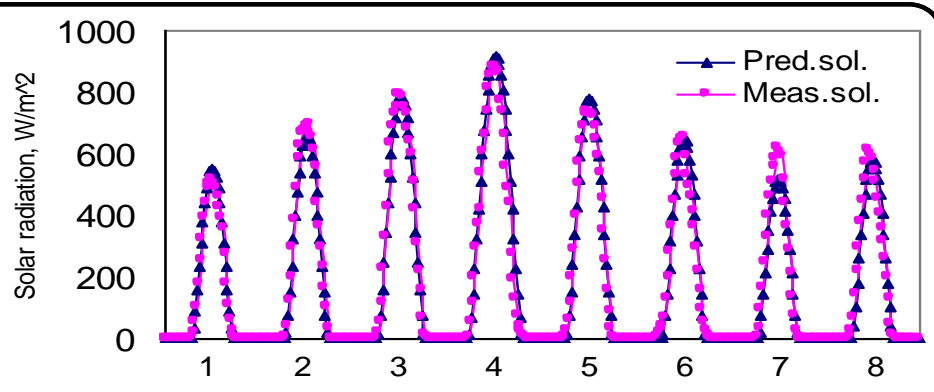

(a

Month
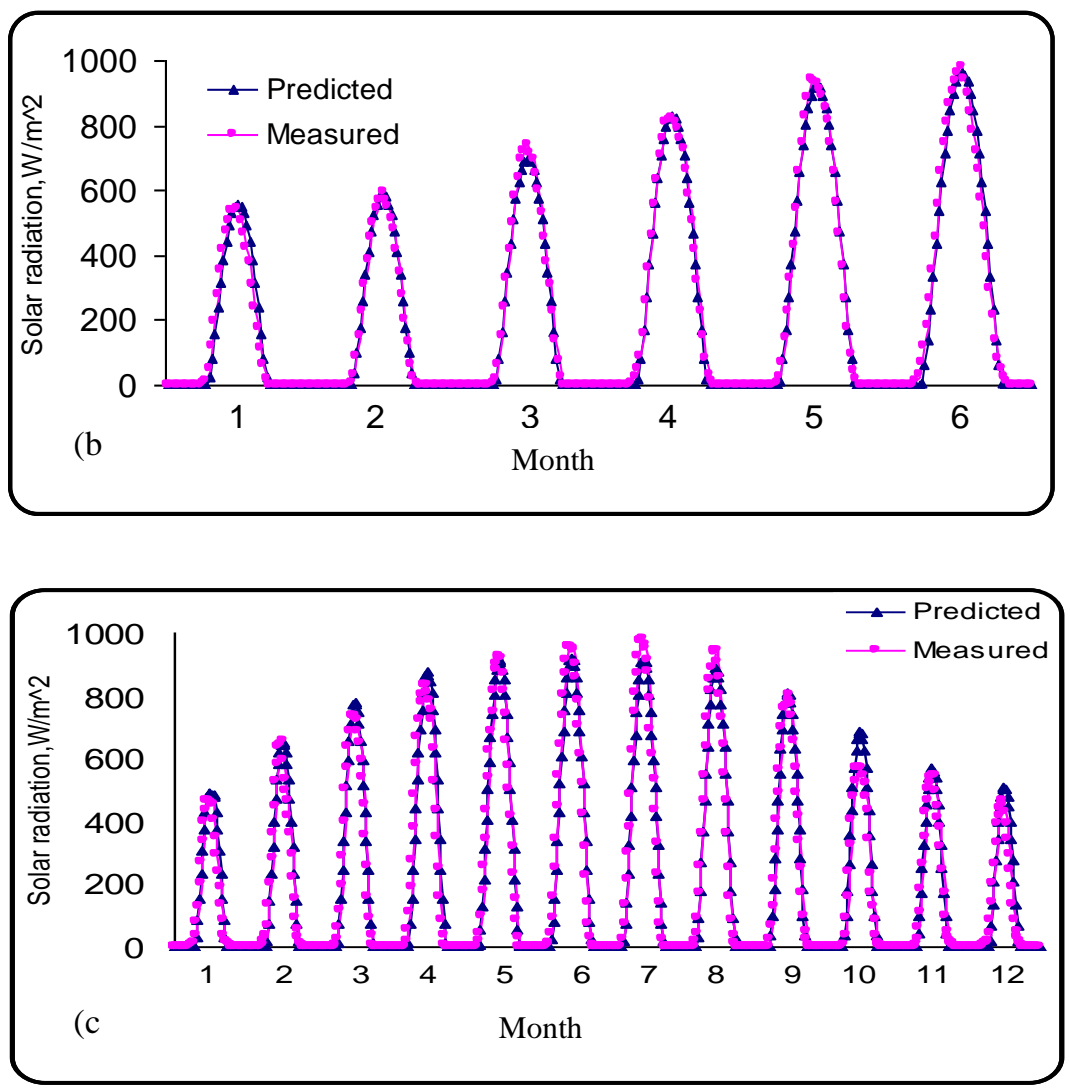

Fig.(2).Diurnal cycles of predicted and measured hourly solar radiation for (a) Shebin Elkom, (b) Belbees and (c) El-Mansoura. 

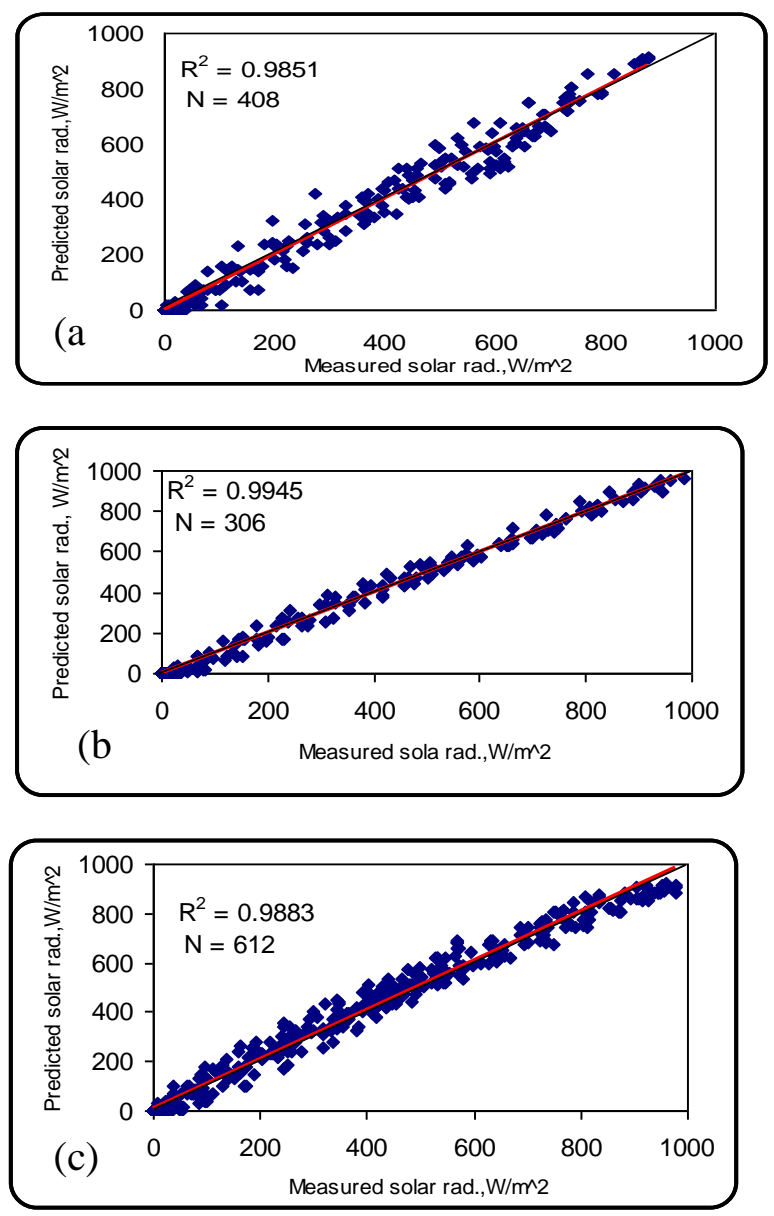

Fig.(3).Comparison between predicted and measured hourly solar radiation for (a) Shebin Elkom, (b) Belbees and (c) El-Mansoura, $\mathrm{N}$ the total number of the observation

Fig.(4) represents the differences between the measured and the predicted values of the hourly solar radiation for during the simulation periods, where it can be seen that the higher difference occurred in the middle of the day and declined late afternoon and early morning. 

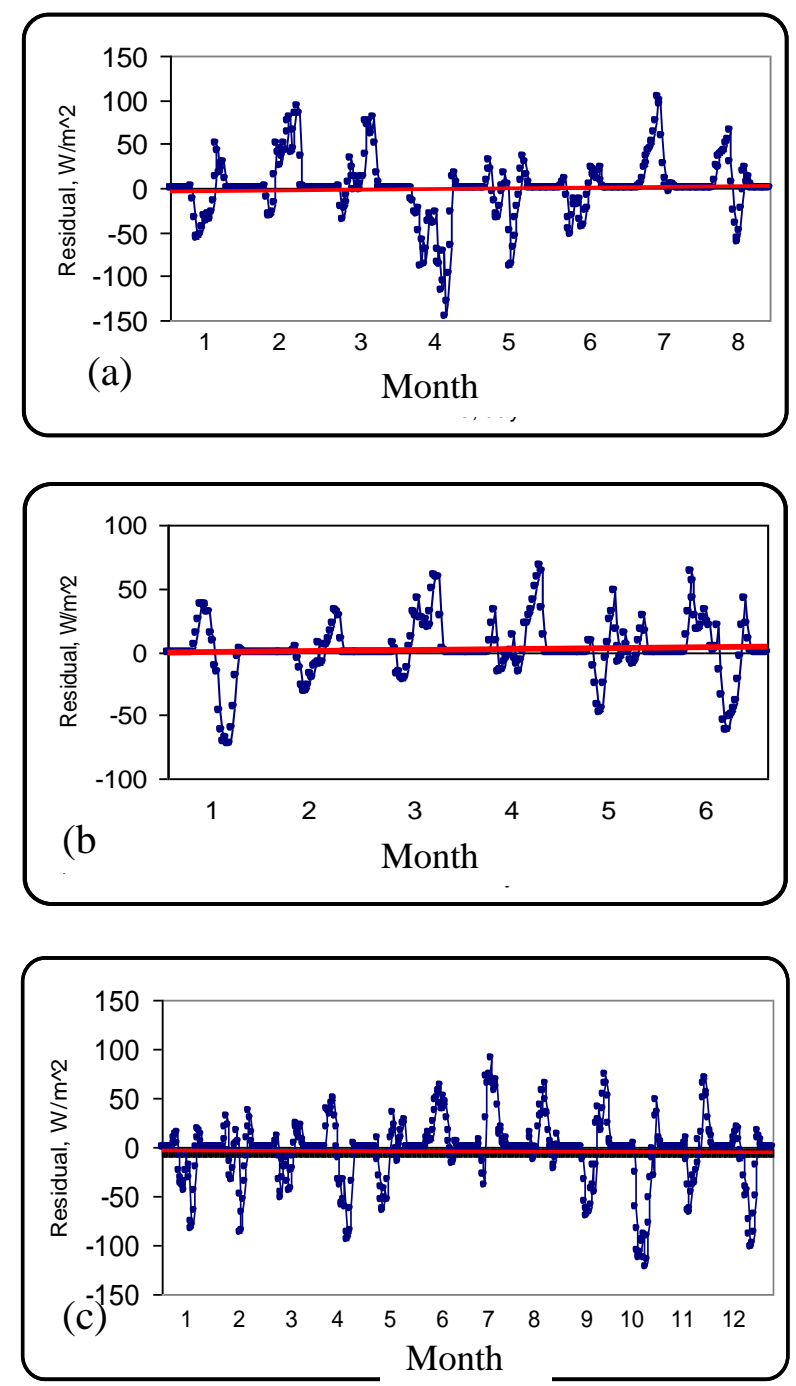

Fig.(4). Residuals of the measured and predicted hourly solar radiation for (a) Shebin Elkom, (b) Belbees and (c) El-Mansoura

The maximum differences between measured and predicted hourly solar radiation profile are $145 \mathrm{Wm}^{-2}$ in June for Shebin El-kom followed by El-Mansoura $120 \mathrm{Wm}^{-2}$ in October while it is $75 \mathrm{Wm}^{-2}$ in January for Belbees respectively. However, the errors obtained are similar to the common solar radiation modeling.

In context of studies of hourly solar radiation in this model, the distribution of the residuals of the hourly solar radiation as a function of 
measured data were plotted Fig.(5). It can be observed that, the points are scattered above and below the zero line, if all points are considered together, the residual was not increase with increasing of the solar radiation Fig.(4) for the all selected regions.
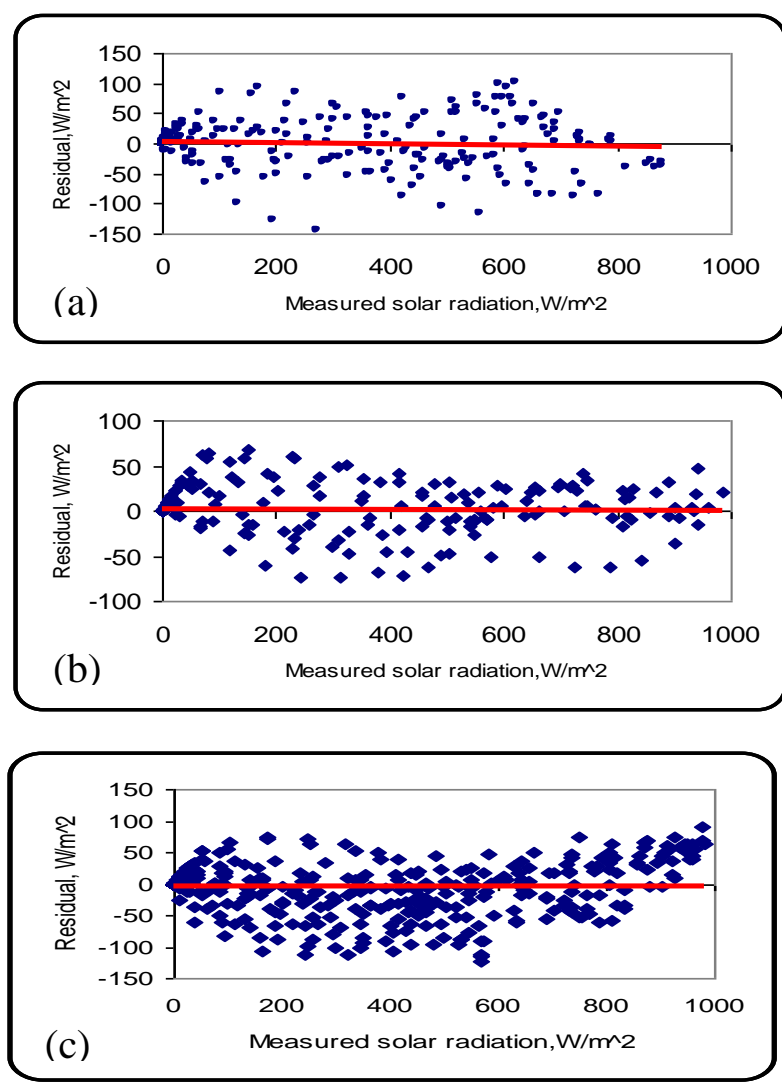

Fig.(5). Plot of residuals (predicted - measured) hourly solar radiation versus measured solar radiation for (a) Shebin Elkom, (b) Belbees and (c) El-Mansoura

\section{CONCLUSION}

A simple model for simulating hourly solar-radiation was suggested in this study. The proposed model can be used for predicting accurately hourly solar-radiation, which helps in the estimation of the long-term performances of solar-energy systems. 
The model is tested for 3 provinces of Egypt. It was seen that the statistical indicator for the model such as correlation coefficient are at acceptable levels. Comparison of the model with the measured data revealed that the model provides predictions in good agreement with the measured data. It is expected that the model developed for hourly solar-radiation will be useful to the engineers of solar-energy related systems as well as those who need to have fairly good estimates of yearly variations of daily global solar-radiation for specific location.

\section{REFERNCES}

Chegaar, M. and A. Chibani, ( 2001). Global solar radiation estimation in Algeria. Energy Conversion and Management 42, 967-973.

Decarli, F., C. Groppi, R. Festa, and C. F. Ratto, (1986). Procedure to obtain global radiation maps from sunshine duration at isolated station in a region with complex orography . Solar Energy ,37 (2):91-108.

Dorvlo, A. S. S. , J. A. Jervase and A. Al-Lawati (2002). Solar radiation estimation using artificial neural networks. Appl Energy;71:307-19

Duffle, J.A. and W.R. Beckman, (2006). Solar engineering for thermal processes. $3^{\text {rd }}$ ed., John Wiley and Sons. Inc., New York. NY.

Elminir, H. k., A.E Ghitas, F. El-Hussainy, F. Hamid, M.M. Beheary, and K.M. Abdel-Moneim, (2006). Optimum solar flat-plate collector slope:Case study for Helwan. Egypt Energy Conversion and Management, $47: 624-637$

El-Sebaii, A. A. and A. A. Trabea,( 2003). Estimation of horizontal diffuse solar radiation in Egypt. Energy Conversion and Management; 44, 2471-2482.

El-Sebaii, A. A. and A. A. Trabea,( 2005). Estimating global solar radiation on horizontal surfaces over Egypt. Egyptian Journal of Solids; 28, 163-175.

El-Metwally, M.(2005). Sunshine and global solar radiation estimation at different sites in Egypt. Journal of Atmospheric and SolarTerrestrial Physics; $67: 1331-1342$.

Gopinathan, K. K.( 1992). Estimation of hourly global and diffuse solar radiation from hourly sunshine duration. Solar Energy; 48(1):3. 
Gopinathan, K.K., (1988). A general formula for computing the coefficients of the correlation connecting global solar radiation to sunshine duration. Solar Energy, 41, 499-502.

Halouani, N., C.T. Nguyen and D. Vo-Ngoc, (1993). Calculation of monthly average global solar radiation on horizontal surfaces using daily hours of bright sunshine. Solar Energy, 50, 247-258.

Heindl, W. and H.A. Koch, (1976). Die Berchnung von Sonneneinstrahlungsintensitäten für wärmetechnische Untersuchungen im Bauwesen. Gesundheits -Ingenieur, 97 H.12,301-314.

Hottel,H. C. ( 1976) . A simple model for eastimating the transmittance of direct solar radiaton through clear atmospheres. Solar Energy $.18(2): 129-134$.

Ibrahim, S. M. A.( 1985). Predicted and measured global solar radiation in Egypt. Solar Energy;35(2):185-8.

Jacovides, C.P., F.S. Tymvios, V.D. Assimakopoulos, and N.A. Kaltsounides, (2006).Comparative study of various correlations in estimating hourly diffuse fraction of global solar radiation. Renewable Energy ,31, 2492-2504.

Liu, B. H. Y. and R. C. Jordan, (1963). The long-term Average Performance of Flat-plate Solar Energy Collectors. Solar energy, 7,53

Palm, W. J. (1999). Matlab for engineering applications. WCB, McGraw-Hill.

Parker, B.F. (1991). Energy in World Agriculture, Solar energy in Agriculture. Elsevier Science Publishers, New York, 1-66.

Sen, Z. (2008). Solar Energy Fundamentals and Modeling Techniques, atmosphere, environment, climate change and renewable. Springer-Verlag London Limited.

Tadros, M. T. Y.(2000). Uses of sunshine duration to estimate the global solar radiation over eight meteorological stations in Egypt . Renewable Energy, 21 : 231-246.

Trabea, A.A. and M. A. Mosalam Shaltout, (2000). Correlation of global solar radiation with meteorological parameters over Egypt. Renewable Energy, (21) :297-308. 


\section{الملخص العربيى}

\section{نموذج رياضي لتقدير الإشعاع الشمسي الساعي الكلي في مصر أحمد توفيق طه*}

يهدف هذا البحث الي تطوير نموذج رياضي باستخدام الكمبيوتر لتقدير متوسط الإشعاع الثمسي الثي

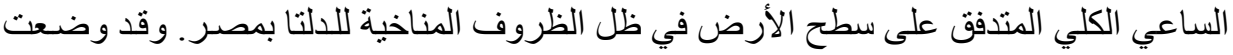

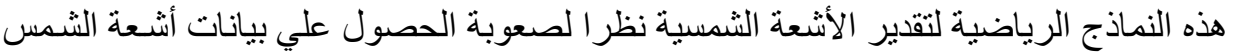

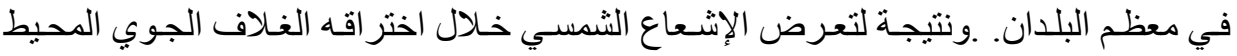

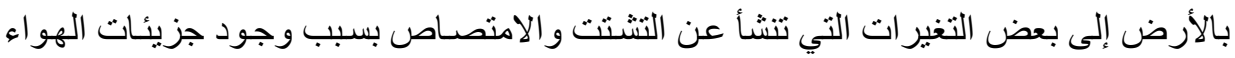

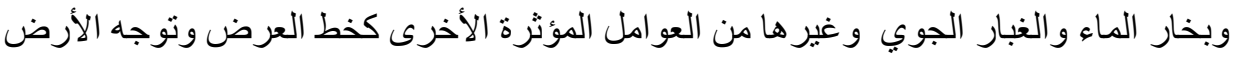

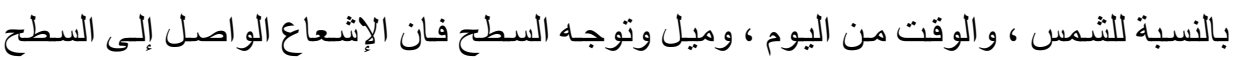

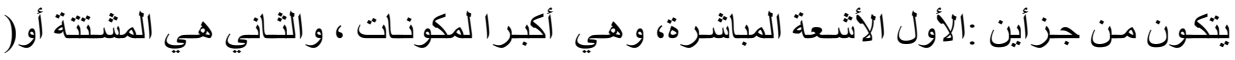

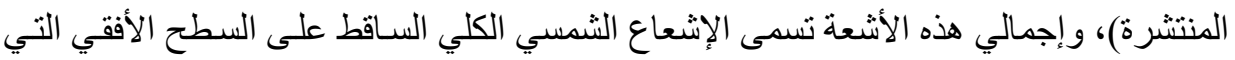

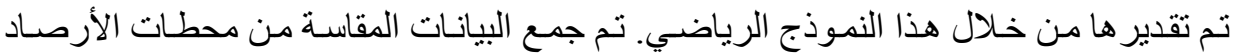

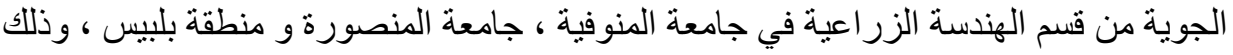

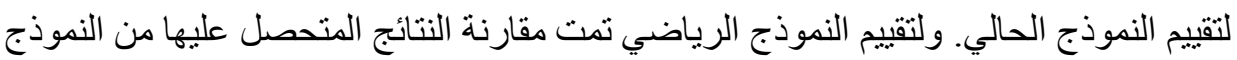

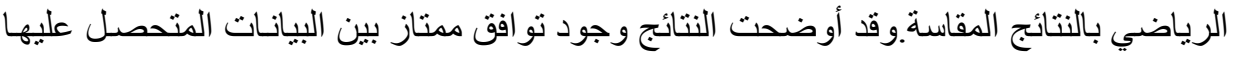
من النموذج والمقاسة للإشعاع الشمسي الكلي الساقط على السطح الأفقي لمناطق الدراسة. يمكن الاستتتاج بـأن النمـوذج المقترح يصلح لتقدير متوسط الإشـعاع الثمسـي السـاعي الكلي المتدفق على سطح الأرض لمنطقة المنوفية ، المنصورة ، ولئبيس. 